\title{
Research on the Cultivation Mode of Innovative Applied Talents in Agricultural Engineering in Local Agricultural Colleges and Universities \\ Yanling Teng ${ }^{1, a}$ and Limei Chen ${ }^{2, b, *}$ \\ ${ }^{1,2}$ Xincheng Street 2888, Jilin Agricultural University, Changchun, Jilin Province 130118, PR China \\ 447568174@qq.com \\ * The Corresponding author
}

Keywords: Higher agricultural colleges; Agricultural engineering; Innovative application type

\begin{abstract}
The State Council issued the plan of national education development in 13th Five-Year "proposed by way of cultivating innovative talents to improve the education quality of our country, and for China to develop a socialist builders and successors. At the same time, in order to respond positively to the national policy on building a new socialist countryside, Jilin Agricultural University, as a local agricultural institution, should follow the training objectives of innovative applied talents and cultivate agricultural talents for the society. This paper mainly analyzes the status situation and problems of cultivating innovative talents in agricultural engineering specialty, and puts forward the specific training mode of innovation and application talents.
\end{abstract}

\section{Introduction}

Jilin Agricultural University agricultural engineering major include: agricultural mechanization and automation, mechanical design and manufacturing and automation, transportation (automotive applications), new energy science and engineering agriculture building environment and energy engineering (construction and environmental direction) and automation and so on. However, the agricultural engineering specialty has a strong professional, wide disciplines, the application of technical capacity requirements and high demand and other characteristics ${ }^{[1]}$. Therefore, in order to meet the requirements of the socialist market economy for the talent, the current agricultural engineering professional training of undergraduate talent not only engaged in modern agricultural engineering technology, innovative talents need a large number of directly to the production line of the promotion and management of the application of talent ${ }^{[2]}$.Innovative application talents are more close to the actual production of agricultural engineering than the research talents, but also have the technical ability to solve the practical problems in the process of agricultural engineering production. Therefore, it is one of the problems that local agricultural colleges and universities can continue to solve by cultivating innovative talents of agricultural engineering.

\section{The Status Situation and Problems of Cultivating and Cultivating Talents of Innovative Talents in Agricultural Engineering}

Innovative Application-oriented Talent Education Philosophy in the Form of, Difficult to Carry Out. Thinking and ideas of innovation is to cultivate innovative application of one of the prerequisites. Nowadays, teachers in local agricultural colleges and universities still uphold the teaching idea of the past, pay attention only to the guidance of students 'knowledge instilling and practice practice, neglecting the cultivation of students' knowledge and skills in combination with the spirit of the times. However, despite the fact that some institutions have educated students on innovative and applied courses, the lack of systematic curriculum system, professional faculty and the lack of practical application platforms have led to the development of innovative application talents stagnant.

The Lack of Professional and Innovative Application of Teachers. Local agricultural colleges and universities in the agricultural engineering teachers teaching tasks are generally heavier, in addition to the normal classroom knowledge teaching tasks, but also need to lead students to 
practice training courses and other training. Teachers will spend more time on research, rather than take the initiative to learn the system of innovative knowledge, let alone teachers take the initiative to improve professional and technical capabilities.

Innovative Application Curriculum Set Goals Are Not Clear, Teaching Content Theory of Light Practice. At present, most of the local agricultural colleges and universities agricultural engineering professional training program basically follow the discipline system construction, professional course selection, credit and assessment mechanism is basically the same ${ }^{[3]}$. Therefore, agricultural engineering in different local agricultural colleges and universities lack the local characteristics, not combined with the actual characteristics of local agriculture, not combined with the characteristics of students in accordance with their aptitude. At the same time, because of the old teaching content, the teaching method is single, the structure arrangement between the specialized theory and the practice course is not reasonable ${ }^{[4]}$.So that students with innovative practical ability for the general capacity of the General Assembly did not improve, resulting in students after graduation despite the rich theoretical knowledge, but the lack of practical ability to exercise, the lack of knowledge creativity and flexibility of the use, resulting in not well adapted The needs of the market ${ }^{[5]}$.

\section{The Agricultural Engineering Professional Innovation Application Talents Training Mode}

Update the Concept of Personnel Training, Pay Attention to Establish Interdisciplinary Training Students the Idea. The training of agricultural engineering professionals should meet the needs of the society and the market, to serve the agricultural economic development of Jilin Province, to provide social needs of agricultural engineering talents. This requires the school to adhering to the "heavy foundation", "wide caliber", "wide adaptation" and "high quality and high capacity" principle to carry out teaching work. With the increasing demand for compound, applied and innovative talents in society, the way of cultivating talents through interdisciplinary and interdisciplinary disciplines has been gradually promoted. In addition to the agricultural engineering students to carry out professional knowledge teaching, but also through the psychology, mechanics and other disciplines of professional knowledge to develop students' comprehensive quality ability. This interdisciplinary approach to cultivating talent can exercise students' creative thinking, which is conducive to improving and improving learning and innovative ways to develop new areas. Through the integration of professional knowledge system and interdisciplinary knowledge system, it is convenient for the students to master the internal structure between knowledge and improve the students' creative thinking ability and application technology ability ${ }^{[6]}$.

According to the Creation of Application-oriented Personnel Training Requirements, the Formation of a Strong Application of Innovative Teachers. Strong ideological quality, title structure and academic structure is reasonable, while both strong ability to create and practical application of the ability to "double teacher" team is to cultivate innovative application talents important guarantee ${ }^{[7]}$. Therefore, the school to "the introduction of talent, training the backbone, to encourage learning, improve quality" as the leading ideology, agricultural engineering teachers in the school and the school's support, and actively participate in domestic and foreign scholars, training, to the factory line learning practice Skills and other means to improve the quality of teachers. In addition, agricultural engineering teachers should also be under the grassroots level to the countryside, as grass-roots agricultural engineering machinery consultant, so skilled professional knowledge and practical experience combined. At the same time, the use of creative ideas to continuously improve their application of technical capacity, and thus promote the teacher's own application of technology to create a comprehensive knowledge and ability to enhance.

To Build a Scientific and Rational Curriculum Teaching System. Taylor has pointed out the curriculum goal model, that is, the school curriculum in the process to follow the following: First, determine the target, agricultural engineering profession according to social demand, with the goal of cultivating applied skills, at the same time, according to the spirit of the times, the spirit of innovation and the training goal of applied talents in fusion. Second, the choice of experience, the choice of experience should include three dimensions: professional knowledge, social life 
experience and learning experience. Re-organization of experience, that is, the content of the curriculum to integrate theoretical knowledge, application skills and innovative spirit, to meet the interests and needs of students, but also to ensure that the professional structure between the disciplines of reasonable. Finally, the results of the evaluation, in the development of innovative application-oriented curriculum, to effectively organize the teaching effect and teaching feedback evaluation, so as to ensure the normal development of the teaching system.

Therefore, we should focus on cultivating innovative talents for the development of agro-economic development in Jilin Province, scientifically formulate the training objectives and concrete implementation plan, and formulate a curriculum training system suitable for innovative talents of agricultural engineering specialty, especially for knowledge theory And the allocation of practical ability to pay attention to the rationality of the structure. So as to design a set of very unique training and application of innovative talents of the detailed program.

Highlight the Professional and Technical Capabilities, the Establishment of A Solid Practice Platform. In addition to highlighting the professional knowledge theory ability, it should also establish the laboratory and practice teaching evaluation system as the basis, to improve the student science and technology activities and other competition mechanism as a springboard to the school enterprises cooperation as an important means of the trinity of the practice training platform. Specifically include the following:

1.Reform of agricultural engineering professional laboratory management system: Jilin Agricultural University agricultural engineering specialty with a provincial experimental teaching demonstration center, three school-level experimental teaching demonstration center, a provincial excellence engineer training program pilot professional, three school-level excellent teaching team. The establishment of these experimental centers, the effective integration of laboratory laboratory resources, is conducive to improving the quality of experimental teaching. Therefore, in the management of the laboratory, in addition to the management of experimental administrators and experimental teachers, but also can take two-way selection, merit appointments, encourage Dr. and professor and other high-level personnel as laboratory management director, thus optimizing the laboratory management.

2.Improve the practice of teaching management mechanism, improve the practice of teaching evaluation system: to strengthen the experimental center of digital management platform to improve the experimental teaching of modern management tools, the use of multimedia technology to enrich the laboratory teaching content. Pay attention to the monitoring and feedback evaluation in the course of practice teaching, adjust the teaching content and teaching method of the practice course according to the feedback result of the students, so as to guarantee the orderly practice of the practice teaching.

3.Establish and improve the various scientific and technological innovation activities competition mechanism to improve the ability to apply innovation: According to the actual situation of agricultural engineering, through the establishment of the corresponding material and spiritual incentive mechanism to fully mobilize teachers to engage in innovative application activities of the initiative and initiative through the competition ranking Offset the corresponding credit mechanism, to stimulate students to participate in creative application of interest. Encourage and guide students to actively carry out scientific and technological innovation activities.

4.To establish a school-enterprise cooperation mechanism: to strengthen the school-enterprise cooperation to develop personnel to explore the mechanism to encourage enterprises to go to school for teaching part-time, which is conducive to the enterprise's excellent resources into the school, and in accordance with corporate standards to organize curriculum content, will help the school and the social needs of the combination, so as to cultivate the application of talent. At the same time to encourage teachers to go to the enterprise to study part-time, which helps teachers to better apply theoretical knowledge in practice, and constantly improve their practical ability, and in the course of practice to develop their own innovative ability, continue to create application teachers Move forward. 


\section{Acknowledgements}

The research project of higher education reform in Jilin province (2016): A Study on the cultivation mode of innovative talents of Agricultural Engineering in local agricultural colleges

\section{References}

[1] Hou Jialin, Li Tianhua, Fu Chenjia, Wang Zhen, Zhang Jun. Agricultural engineering undergraduate professional application of talent training research and practice [J]. Higher Agricultural Education, 2012, (04): 41-44.

[2] Li Xiang, Guo Haifu, Liang Qiaolong, etc. Chemical industry application talents training mode field [J]. Guangdong Chemical Industry, 2010.37 (3): 233 -234.

[3] Wang Yang. Innovative application of undergraduate talent training model [J]. Technology and Innovation Management, 2016, (03): 340-343.

[4] Gao Chaofeng, Sun Xiangyang, Li Li.Study on the Cultivation Mechanism of Applied Innovative Talents in Local Colleges [J]. China Electric Power Education, 2009, (07): 12-13.

[5] Wang Junfa, Wei Tianlu, Zhu Xiangdong.Study on the Cultivation of Innovative Applied Talents in Engineering College Students [J] .Heilongjiang Education (Higher Education Research and Evaluation), 2013, (05): 58-59.

[6] Wang Qingguo. Analysis of local colleges and universities to cultivate innovative talents [J] .China Light Industry Education, 2013, (01): 53-55.

[7] Liu Chunyan, Qu Erguang, Niu Wangjie. Discussion on the Training Mode of Innovative Applied Talents in Mechanical Specialty [J]. Journal of Yuncheng University 2011 (05): 79-81. 